\title{
The evolution of (proto-)language: Focus on mechanisms
}

\section{Keywords}

Origin of language

Evolution of language

Protolanguage

Mechanisms and processes

Language origins

Language evolution

\begin{abstract}
A B S T R A C T
This article introduces a special issue on mechanisms in language evolution research. It describes processes relevant for the emergence of protolanguage and the transition thereof to modern language. Protolanguage is one of the key terms in the field of language evolution, used to designate a hypothesised intermediate stage in the emergence of language present in extinct hominins: qualitatively different from non-human primate communication in possessing some, but not all, of the features that characterise modern language. Much debate in language evolution focuses on the exact delineation of these features, as well as the means whereby the transitions occurred: first from non-human primate communication systems to protolanguage, and then from protolanguage to modern language. In what follows, we first propose a comprehensive typology of protolanguage debates, taking into account the postulated structural organisation of protolanguage, its functions, and its communicative modality. This makes it possible to show how a specific focus on mechanisms and processes deemed relevant for the emergence of these features allows us to assess the explanatory scope of the existing theories of protolanguage.
\end{abstract}

(c) 2017 Elsevier Ltd. All rights reserved.

\section{Introduction}

Studying the evolution of language is notoriously troubled by a paucity of tangible evidence on its biological and sociocultural origins. We can distinguish animal communication systems from modern-day languages, but scholars continue to disagree on whether or not the former have continuity with the latter, and whether such (dis)continuity results from biological (genetic, anatomical and neurocognitive) or sociocultural mechanisms, or a combination of both. Much, of course, depends on definitions. A useful way of dividing the territory between animal communication systems on the one hand and modern human language on the other is by proposing a middle-ground, and this aim is achieved by the construct of protolanguage: a hypothetical communication system that has some, but not all, features considered to be necessary for language. ${ }^{1}$ (see Section 3)

Although the concept of protolanguage is generally accepted in language evolution research (cf. e.g. reference works and overviews, e.g. Fitch, 2010; Tallerman, 2011), opinions differ on what exactly constitutes the essential features of language, and which of them should be present in protolanguage. As we will demonstrate in this introduction, ongoing debates mostly focus on the structure (combinatorial vs. holistic), function (communicative vs. representational) and modality (speech-first, gesture-first, multimodal-first, pantomime-first) of protolanguage. In this issue, contributing authors concentrate on the mechanisms and processes that underlie the evolution of protolanguage. A focus on mechanisms provides new perspectives

\footnotetext{
${ }^{1}$ Note the difference from the standard use of the term proto-language in historical linguistics, where it denotes a reconstructed ancestor-language of a language group.
} 
on the biological, cognitive and social processes involved in the evolutionary emergence of protolanguage and its transition to language.

In general, any identification of a mechanism involves a determination of the conditions whereby a change in a phenomenon occurs, which typically involves finding the causal factors that underlie specific outcomes. ${ }^{2}$ While there exists a vast literature on what evolutionary mechanisms are and how they induce change (Bechtel, 2011; Campbell, 1974; Dennett, 1995; Lewontin, 1970; Machamer et al., 2000; Okasha, 2006), these discussions are mostly held within philosophy of science and evolutionary biology where they relate to general debates on the nature of natural selection. What scholars identify as a mechanism relevant to the evolution of (proto)language can be defined in a multiplicity of ways. As the contributors to the present special issue show, these conditions need not always and exclusively be biological, and beyond natural selection, we can identify cognitive and sociocultural mechanisms that underlie the evolutionary trajectory from animal communication systems to protolanguage and from protolanguage to modern language.

\section{Protolanguage - a changing perspective}

Traditional language origins literature, paradigmatically represented by the Enlightenment thinkers, already contains rich intuitions about a possible intermediate stage en route to a fully fledged language: the emergence of the latter was thought to have been preceded by ancient systems of communication and thought, such as "dance of gestures and steps" in the Mandeville-Condillac proposal or, as suggested by Herder, cries motivated by innere Sprache - our ancestors' symbolic ability. However, the term "protolanguage" was first used in works today classified as "modern" language evolution literature: it was introduced by Gordon Hewes (1973) and later made popular by Derek Bickerton (1990: 122-125). On the latter account, it denoted a quasi-linguistic representational system existent and evolving possibly from Homo habilis (circa 2.4-1.5 million years ago) and Homo erectus (circa 1.9-0.2 mya) onward, which is characterised by the lack of morphosyntax and the presence of units equivalent to lexical items.

The idea of protolanguage found an influential opponent in Noam Chomsky, whose view of the language faculty as something uniquely human and radically different from animal communication systems (e.g. Chomsky, 1965) precluded a possible protolinguistic stage (e.g. Chomsky, 2011). Chomsky and co-workers (e.g. Hauser et al., 2002) now accept that many aspects of the Faculty of Language in the Broad Sense (FLB) - which includes the sensori-motor system and the conceptualintentional system - have continuity with and thus at least partial evolutionary precedence in other hominins, non-human primates, and possibly other animals. This does not apply to the Faculty of Language in the Narrow Sense (FLN), which is not primarily characterised by a lexicon, but by the syntactic ability to recursively form potentially infinite combinatorial sets from finite lexical items - a capacity in turn attributable to a cognitive operator called Merge. Merge is a cognitive-computational procedure that enables such combinatorics, and it is assumed to be hardwired in the brain and genetically underpinned (Berwick and Chomsky, 2016). Since the possession of Merge is all-or-nothing, the Faculty of Language in the Narrow Sense (FLN) could not be preceded by a protolanguage.

In contrast, the mainstream view in language evolution is more gradualistic and assumes incremental growth of language (e.g. Pinker and Bloom, 1990; Jackendoff, 2002; Hurford, 2007; Arbib, 2012):

- from the initial point identified with the systems of communication and thought inherited from the LCA-c (the Last Common Ancestors humans shared with chimpanzees; Arbib, 2012);

- through the intermediate stage of hominin protolanguage, which on the one hand represented a qualitatively new form of communication (and thought) but on the other lacked in complexity and/or expressive power when compared to fully fledged language;

- the endpoint, i.e. modern language.

As for the mainstream, the last decade of the 20th century in language evolution research was dominated by generating scenarios of language emergence, in a way not dissimilar to traditional theorising about language origins (see Zywiczynski and Wacewicz, 2015, Chapter 3). The protolanguage concept was used as an important instrument in these attempts. Dunbar's "grooming scenario" (1996), for example, whereby language emerged as a more efficient means of social grooming, emphasised that protolanguage must have originated as a vocal system and that "vocal grooming" was much more efficient than manual grooming for negotiating increasingly complex social relations in expanding hominin groups. But already in the 1990s and early 2000s there was a growing realization that it is difficult to squeeze the evolutionary emergence of such a complex adaptive system as language into the confines of a single scenario. More and more research was oriented toward uncovering constraints on existing scenarios (cf. Johansson, 2005; Wacewicz and Zywiczynski, 2012).

Related to this development has been the change of focus, from purely conceptual work to empirical work based on first-hand data collection (see e.g. Dediu and de Boer, 2016; Fitch, 2017). Language evolution as a field was already based on empirical findings, but this relation was to a large extent only vicarious. This has changed over the last decade, when

\footnotetext{
2 Cf. e.g. Miłkowski (2016: 46) "While there are multiple definitions for the term mechanism, the core idea is that a mechanism is an organized system that comprises causally relevant components and operations (or activities). Component parts of the mechanism interact, and their organized operation contributes to the capacity of the mechanism to exhibit [a phenomenon] $\varphi . "$
} 
language evolution researchers began acquiring data to test their hypotheses directly through their own laboratory work, most importantly with semiotic experiments, i.e. "the experimental investigation of novel forms of human communication... which people develop when they cannot use pre-established communication systems" (Galantucci and Garrod, 2011). In particular, experiments on the cultural evolution of communication systems have afforded insight into the emergence of such linguistic features as compositionality (Kirby et al., 2008; see also Beckner et al., 2017) but also into the expressive power and contextual limitations of various modalities used for communication (Fay et al., 2013). Experimental semiotics has also shown that communication without language has different expressive power in different modalities, such as non-linguistic vocalisation (e.g. Perlman et al., 2015), improvised gesture (e.g. GoldinMeadow et al., 2008), pantomime (e.g. Zlatev et al., 2017), or the combination thereof (e.g. Fay et al., 2013, 2014; Zlatev et al., 2017).

\section{Types of protolanguage: a classification of current debates}

As Smith (2008: 99) points out: "[m]ost scholars agree that there must once have been a predecessor of human language, or protolanguage, which did not contain the complex syntactic structures prevalent in modern languages..., but they disagree vehemently over the nature of protolanguage, and over how it developed into modern human language". Here, we categorise such disagreements along the following, partly independent, dimensions:

- function of protolanguage (whether it enabled inner thought or communication with conspecifics; if the latter, whether it served communication of semantic content or musical-emotional expression);

- structure (whether its units were approximately lexeme-size or proposition-size); and

- modality (vocal, gestural, multimodal or pantomimic) (Table 1).

Table 1

The axes of protolanguage debates represent our own, necessarily simplified, classificatory proposal designed to organise this area of language evolution research under three rubrics - structure of protolanguage, its dominant function and communicative modality (or modalities); it should be noted that the problem of modality arises only on the assumption that protolanguage was used for communication.

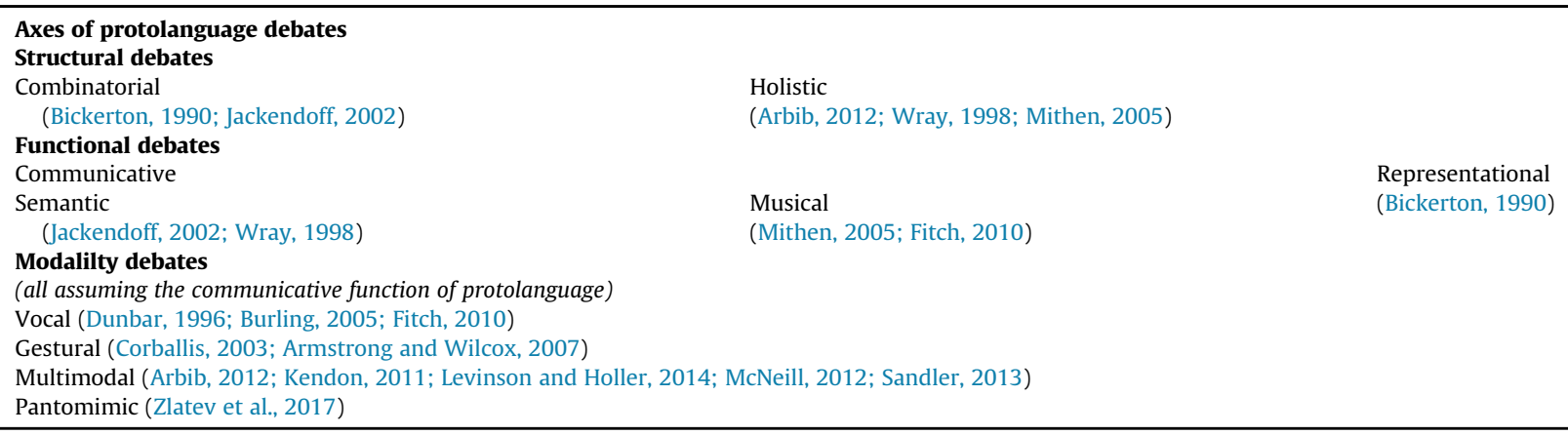

Most commentators (e.g. Fitch, 2010: 399-507; Tallerman, 2011) rely on similar labels, but in closer reference to specific conceptions of protolanguage proposed in the literature, which tend to be pitted against each other as mutually exclusive competitors. Here, we use a different strategy and treat these labels more as general descriptive categories, partly independent of each other and thus mutually nonexclusive. This extends the logical space of possibilities beyond the extant accounts. For example, although a pantomimic protolanguage must by definition be holistic (cf. Zywiczynski et al., 2016), a multimodal protolanguage could conceivably exist with either a combinatorial or holistic structure.

All such classificatory attempts necessarily involve a degree of simplification, because the specific scenarios proposed are nuanced and often envisage several different stages that all qualify as "protolinguistic". For example, Fitch's (2017) phonology-first model is (first) musical but (later) multimodal, and could also be classified as holistic: the first combinatorial units are non-semantic, while the first semantic utterances are holophrases out of which single word-size units need to be extracted. Arbib's and Tomasello's accounts may qualify as pantomimic. Arbib (2012) unambiguously favors a multimodal protolanguage, but indeed with a very important precursor in the form of pantomimic communication. Tomasello's (2008) model is usually classified as "gestural", but with two specific types of "extraoral visible bodily action" (to borrow an expression from Kendon, 2014) leading the way, i.e. pantomime and pointing. And many gesture-first theorists openly admit that "there never was a time when visible gestures were unaccompanied by vocalizations" (Armstrong and Wilcox, 2007: 68). Dunbar's (1996) account is not incompatible with musical accounts (with vocal grooming performing the musical function), while in Mithen's (2005) holistic and musical conception forms of protolinguisitc communication include expressive body movements in the form pantomime and dance.

Beyond these dichotomies, other focal discussion points are whether protolanguage directly and thus continuously evolved from animal sensori-motor, conceptual-intentional and overall communicative systems, and directly evolved into modern 
language, or whether protolanguage is discontinuous with both. If the latter view is adhered to, questions also emerge on whether the former systems were replaced or whether some form of co-evolution occurred. Distinctions are also made based upon the environmental factors that take the biological and sociocultural niche into account wherein protolanguage possibly evolved.

\subsection{Structure}

\subsubsection{Combinatorial vs. holistic}

This dichotomy concerns how protolinguistic meaning was communicated: holistically or combinatorially. Primate communication systems, such as vervet monkey alarm calls (Cheney and Seyfarth, 1988), are often interpreted as holistic and limited because they pack an entire message into a single call. Human language, instead, is characterised by open-ended combinatoriality of discrete lexical items. Based on this, many speech/vocal-first accounts (e.g. Bickerton, 1990; Jackendoff, 2002; Burling, 2005) and some gesture-first accounts (Stokoe, 2001; Corballis, 2002) more or less explicitly assume a protolanguage consisting of lexical units (either vocal or signed); on such a view, it is the appearance of generative morphosyntax that would have marked the transition from protolanguage to language.

The less intuitive alternative, which better explains the continuity of language with primate communication, is that protolanguage was originally holistic, with utterance-like units referring to complete events (Wray, 1998; Mithen, 2005). Wray and Grace (2007) propose two primary niches of language use - exoteric, which serves to communicate with non-group members, and esoteric, reserved for closely-knit groups where members share extensive common ground - and argue that in the latter, communicative success depends more on pragmatic factors than on explicit and structurally complex verbal strings. Assuming that protolanguage must have emerged in esoteric niches, they conclude that semantic compositionality may be but a secondary characteristic of language, resulting from an adaptation to the exoteric niche. Interestingly, their insight finds some support in cross-linguistic studies based on big databases, such as The World Atlas of Linguistic Structures (WALS Online - Dryer and Haspelmath, 2011); and Lupyan and Dale (2010) have demonstrated that languages spoken by small, isolated populations tend to be morphologically overspecified (i.e. have a high degree of redundancy resulting from the complexity of their inflectional morphologies). Holistic accounts have, however, attracted criticism because they seem plausible only on the assumption of rather stringent criteria, most importantly a small repertoire of signals (see e.g. Tallerman, 2008), a point supported by computer simulations (e.g. Johansson, 2008).

\subsection{Function}

\subsubsection{Representational vs. communicative}

Bickerton (1990) notes that animal communication systems are always directly associated with real-life events. In contrast, protolanguage constitutes a "primary representation system", made up of symbolic units which enable new ways of categorising and conceptualising experiences to the self. Only derivatively does a "secondary representational system," such as a verbal lexicon or externalized language, make it possible to communicate these representations to conspecifics. Many scholars involved in theorising on the nature of protolanguage, however, ignore this important element of Bickerton's theory and instead exclusively focus on the social and thus communicative power of a protolinguistic system (e.g. Pinker, 2003; Wray, 1998; Dunbar, 1998).

\subsubsection{Semantic vs. musical}

The views that argue for the primacy of the communicative function can be further subcategorised on the basis of what they take to be the communicated content. The dominant position is that protolanguage - like language today - primarily served to transmit semantic content, i.e. ideas or configurations of ideas. In this sense, both the combinatorial, lexicon-based accounts of Bickerton (1990) and Jackendoff (2002) as well as Wray's (1998) holistic conception of protolanguage (see below) can also be understood as semantic theories. This semantic quality distinguishes them from most musical accounts, where protolanguage is primarily seen as a vehicle of emotional and musical expression, often in the context of sexual selection. Musical interpretations of protolanguage have an eminent patron in Charles Darwin, who in The Descent of Man (1871) hypothesised that language began with songs produced by our ancestors for emotional display and courtship; Jespersen (1922) espoused a similar view. Contemporary proposals include Fitch's theory of bare phonology (2010), which likens the first forms of protolinguisitc communication to birdsong, which has a high degree of (hierarchical) combinatoriality and generativity but lacks propositional content. For Fitch, bare phonology was a direct precursor to syntax. Another account is Mithen's (2005) Hmmmm-theory that conceptualises protolanguage as holistic, manipulative, multi-modal, musical and mimetic. Holistic expressions are taken to possess important musical characteristics, and music and language are argued to trace back to a common set of cognitive abilities (e.g. musilanguage in Brown, 2001).

\subsection{Modality}

\subsubsection{Vocal vs. gestural}

The vast majority of the world's languages come in spoken rather than signed form, which serves as a powerful intuitive argument that language must always have existed in the vocal-auditory modality (see e.g. Dunbar, 1996, 1998; Burling, 2005; 
MacNeilage, 2008; Lieberman, 2007). The proponents of the vocal scenarios point toward the large scale of anatomical adaptations for speech, including the descended larynx in humans (Lieberman, 2001; but see Fitch, 2000) that facilitated the appearance of the "double resonator" system comprised of the vertical pharyngeal cavity and the horizontal oral cavity (Nishimura et al., 2003). Perhaps more importantly, speech also turns out to rely on extensive neural reconfiguration relative to nonhuman primates - in particular the development of cortico-laryngeal connections (Deacon, 1992) and an increase in the innervation of the thoracic muscles (MacLarnon and Hewitt, 1999) - traits that are difficult to interpret other than as adaptations for elaborate vocal signalling.

The seemingly less intuitive alternative - the gesture-first approach - in fact has a long history, as it was already present in the speculation of early enlightenment philosophers such as Vico ([1725] 1948) or de Condillac ([1746] 1756). Its more contemporary revival in the form of the gestural primacy hypothesis was due to the anthropologist Gordon Hewes $(1977,1996)$, who in addition to documenting a rich Occidental tradition of speculation about language origins, amassed a large range of evidence favouring a gestural over a vocal protolanguage. His arguments related to handedness, brain lateralization and lefthemispheric domination, a greater iconic potential of visual over vocal signals, and the limitations to voluntarily controlled vocal signalling in non-human apes. Recent advocates mostly build on these insights (e.g. lateralisation, Corballis, 2003; iconic potential: Armstrong and Wilcox, 2007; greater flexibility for intentional signalling in ape gesture vs. vocalisation: Tomasello, 2008). Finally, support for a gesture-based origin of language is also found in emerging research on home signs (Akach et al., 2009; Botha, 2007) and how they can transform into new sign languages de novo, as was the case in the rise of Nicaraguan sign language (Senghas et al., 2005).

\subsubsection{Multimodal-first vs. pantomime-first}

Sign languages, however, present a problem rather than a blessing for the proponents of the gestural view. The difficulty lies in explaining why a gestural protolanguage, rather than staying manual-visual, would have changed its default modality from gestural to vocal in the course of human evolution. Given the fully linguistic status and full functionality of sign languages, pointing to a compelling reason for such a transition turns out to be surprisingly difficult (cf. e.g. Fitch, 2010).

This transition problem (Hewes, 1973, cf. Kendon, 2008) was one motivation behind looking into ways of combining the two competing accounts. Still more incentive came from recent research into communication of monkeys and apes, who turn out to flexibly tap the repertoire of vocal (e.g. vocalisations, lip smacks or mechanical noise) and visual (e.g. manual gesture, body posture, facial expression) semiotic resources, and tactically combine them in a way optimally suited to their current communicative goal (e.g. display vs. secrecy). In short, communication of non-human primates is to a large degree multimodal (see esp. Liebal et al., 2013). In fact, much the same can be said about the human primate. Human communication in its default context - face-to-face conversational interaction - is never unimodal; instead, conversants use the auditory-vocal channel together with the motor-visual channel to transfer two types of information (discrete-segmented and analogmimetic: Goldin-Meadow, 2016) with partly overlapping and partly independent meanings. Such expression is integrated on a very deep cognitive level, to the point of some gesture researchers (e.g. McNeill, 2012) proposing that speech and gesticulation are both manifestations of a single cognitive system. This is why for gesture researchers, most notably Kendon (2011), McNeill (2012), and for some sign language researchers (e.g. Sandler, 2013), no modality change needs to be postulated, because language has been multimodal since its first protolinguistic beginnings.

Despite its many virtues, the broadly stated multimodal perspective suffers from a fundamental limitation: the increase in explanatory power that results from marrying two rival positions comes at a price, as it correspondingly lowers falsifiability (Wacewicz et al., 2016). For this reason, multimodal accounts are only scientifically valuable insofar as they generate testable predictions that would distinguish them from both the gesture-first and speech-first alternatives. One suggestion is offered by Zlatev et al. (2017; cf. Zywiczynski et al., 2016), who distinguish bona fide multimodal-first theories from a related group of pantomime-first theories:

"(A multimodal ...) theory predicts (a) no advantage for any of the modalities in the communication of non-human apes, (b) joint neural control of vocalization/speech and visible bodily communicative action, (c) inseparable connections between speech and gesture/action in language use, (d) co-emergence in child development and (e) more successful communication using multimodal performance than only bodily-visual pantomime in experimental studies.

In contrast, the pantomime-first theory would be more consistent with findings of ( $\left.a^{\prime}\right)$ greater flexibility in bodily over vocal communication in apes, $\left(b^{\prime}\right)$ a degree of dissociation in motor control of speech and pantomime, $\left(c^{\prime}\right)$ partial independence between speech and gesture in use, $\left(\mathrm{d}^{\prime}\right)$ gradual integration of the modalities in development, and $\left(\mathrm{e}^{\prime}\right)$ either no advantage for multimodal performances, or actually advantages for silent pantomimes in experimental settings."

\section{The importance of mechanisms}

The typological debates on the nature of protolanguage discussed above can be complemented by a different perspective afforded by a careful consideration of the mechanisms behind its emergence and transition to full language. Ever since the seminal article by Pinker and Bloom (1990), language evolution has been investigated from a Neo-Darwinian framework, with language understood as an adaptation (Dawkins, 1982) for communication. This view stands in contrast with biolinguistic 
approaches, where language is identified as an exaptation (Gould and Vrba, 1998; Tattersall, 2010) or by-product of a cognitive (r)evolution enabling in particular the capacity to hierarchically and syntactically order thought (Chomsky, 1999).

While adherents of Neodarwinian approaches to language evolution often assume continuity views and endorse the idea that precursors to language evolved gradually and by means of natural selection, adherents of the discontinuity views have been investigating how gene regulatory mechanisms can explain the assumed rapid evolution of linguistic traits from the perspective of evo-devo and epigenetics (Jablonka and Lamb, 1999; Berwick and Chomsky, 2016) or niche construction (Bickerton, 2016). Evo-devo and epigenetics are often presented as rivals to natural selection, but as supporters of the Extended Evolutionary Synthesis demonstrate (Laubichler and Renn, 2015; Pigliucci and Finkelman, 2014), new insights coming from developmental biology and molecular biology do not necessarily oppose natural selection theory per se. They "merely" question the originally narrow assumptions made about the origin of variation, the nature of heredity and the pace of evolution.

In what regards the nature of genetic variation, mutations can be the result of random copying errors in gene replication, and the assumption has long been that adaptive mutations will become naturally selected. But drift theory has demonstrated that neutral mutations are often able to spread more easily than adaptive ones (Masel, 2011). Variation also need not be narrowly defined as gene-based. Developmentally-stable phenotypes, for example, can undergo epigenetic inheritance (inheritance outside the germ line), which can be accounted for by processes such as phenotypic accommodation due to developmental plasticity (West-Eberhard, 2005). Beyond genes, phenotypic and behavioural variation can be subjected to selection processes, and the Baldwin effect that underlies social heredity (Baldwin, 1896) demonstrates that variation can be induced non-randomly, in response to environmental conditions. Such research associates with polemics on the units (Hull, 1980; Dawkins, 1982; Griesemer, 2000; Oyama et al., 2001), levels (Brandon, 1982) and major transitions (Maynard Smith and Szathmáry, 1995) of evolution - debates that are also studied by in evolutionary biology and philosophy of biology (Brandon, 1982; Lewontin, 1970; Okasha, 2005). In this regard, especially notions such as replicators, memes and linguistic replicators or lingueme have been studied in the field of evolutionary linguistics (Christiansen, 1994; Croft, 2000; Szathmáry, 2006; Tamariz and Kirby, 2016; Steels and Szathmáry, 2008). Interestingly, this research has helped extend the very conception of language beyond the narrowly internalistic-individualistic understanding that dominated early language evolution (see e.g. Levinson, 2006; Dediu et al., 2017).

A broader understanding of variation has led to redefining inheritance in order for it to be more "inclusive" and able to take into account these epigenetic, ecological and cultural types of inheritance that influence the course of human evolution (Danchin et al., 2011). As exemplified by Wray and Grace's conception of "niches of language use" (2007; see above), some of the key ideas were also developed in the context of language evolution. Here, especially niche construction (Deacon, 1997; Bickerton, 1990; Wray, 1998) and the role of emulative or cumulative learning (Mesoudi, 2016; Tamariz and Kirby, 2016) or the ratchet effect (Tomasello, 1999) are explored. And in what concerns the gradual pace that Darwin (1859: 94) assumed for the operation of natural selection, the idea that natura non facit saltus ${ }^{3}$ is not one of the logical prerequisites necessary for natural selection to work, as already observed in Huxley's (1900: 27) letter to Darwin.

Nonetheless, a more general and universalised "logical skeleton" of natural selection, summarised by Lewontin (1970) as "differential variation, inheritance, and selection," remains valid in so far as it does not a priori detail how variation and inheritance are construed, or how fast or slow these processes occur. It also opens the door to understanding mechanisms not only as biological, but also as cultural (Mesoudi, 2016) and social (Baldwin, 1896), which raises questions on co-evolutionary or independent evolutionary trajectories of the biological and sociocultural realms (Boyd and Richerson, 1985).

This in turn opens the door to a specific identification of behavioural, neurocognitive, cultural and linguistic mechanisms that underlie the evolution of humankind and its specific traits such as culture and language. The concept of "evolutionary mechanism" need not be reserved to the field of evolutionary biology, and we can at least to some extent identify the evolutionary trajectories going from behavioural, cognitive or linguistic causes to the effects or outcomes they bring forth. In other words, biological mechanisms that induce evolutionary changes are not the exclusive locus of causation, and "proximate" and "ultimate" causes (Mayr, 1961; Tinbergen, 1963) can also be found in behavioural, cognitive, sociocultural and linguistic processes.

For proto-language to emerge, the mechanisms of biological evolution must have produced hominins with a set of peculiar cognitive capacities - to use Arbib's term - a "language-ready brain" (Arbib, 2012). But for these capacities to be used in communicative contexts, biological mechanisms must have likewise led to the emergence of a set peculiar social conditions. In causal terms, these socio-cognitive factors are best understood as conditions enabling and constraining the evolutionary emergence of language.

On the cognitive plane, the onset of (proto)language must have been preceded by the development of a variety of capacities, including trust (Dor et al., 2014), volitional representational abilities (the mimesis theory: Donald, 1991; Zlatev, 2008), mind-reading abilities (Premack and Woodruff, 1978; Tomasello and Call, 1997), metarepresentational thinking (Dunbar, 2007), aspects of memory such as displacement (Deacon, 2012; Hurford, 2012; Tallerman, 2011) or mental time travel (Corballis, 2014; cf. Ferretti et al., in this issue), and executive function related to e.g. inhibiting and allocating attention (Deacon, 1997; Boysen et al., 1996). Social factors are individual- and group-level behavioural processes that appeared after hominins split from apes, which can be causally linked to the emergence of stable environmental niches suitable for the

\footnotetext{
${ }^{3}$ That nature does not jump is an idea that arose in philosophy. Leibniz (1765; New Essays, IV, 16) used it in a discussion of Locke's work on human understanding, and the idea was repeated by Kant. It was introduced into biology in 1751 by Linnaeus (for a discussion see Kirchner, 1890).
} 
evolution of (proto)language. These changes operate on macro- and micro-levels, where they respectively enable individual and group interactions that in turn enable community formation beyond what is seen in chimpanzees. The most central of these is the development of empathy, altruism and "shared intentionality" (Tomasello, 1999, 2008) leading to a type of cooperation specific to hominins (Deacon, 1997; Tomasello, 1999, 2008; Hrdy, 2009), without which language-like communication would not have been able to emerge (Hurford, 2007; Tomasello, 2008; Fitch, 2010; cf. Wacewicz et al., in this issue). Cooperation changed the nature of social interactions, allowing individuals to engage in complex, collaborative tasks (cf. the "human interaction engine", Levinson, 2006).

\section{Language evolution: a diversity of mechanisms}

The articles in this volume discuss a variety of mechanisms of language emergence, giving due attention to biological, cognitive and social causal factors that helped establish the evolutionary trajectory of (proto)language.

In "What are the levels and mechanisms/processes of language evolution?," Nathalie Gontier (2017, this issue) provides a general methodology for how scholars can unify existing datasets and theories on the origin and evolution of language that currently often remain juxtaposed. Central to her approach, which she calls Applied Evolutionary Epistemology, is that the means whereby evolutionary biologists have studied the origin and evolution of life can set the example for how evolutionary linguists can investigate the origin and evolution of language. Beyond the general application of selection theory to anatomical form and functional behaviour, evolutionary biologists nowadays work from within an extended evolutionary synthesis. Taking on a pluralistic stance, they search for units (elements that evolve), levels (loci where these elements evolve) and mechanisms of evolution (the means whereby elements evolve at certain loci). Gontier analyses how traditional linguistic schools, cognitive linguists, biolinguists, evolutionary psychologists and adherents of gene-culture coevolutionary theories have, either implicitly or explicitly, been engaged with identifying the elements or units that underlie animal communication skills and the human language faculty, and how they have debated the levels or loci where they are of relevance (e.g. the brain, the body, the species, culture, etc.). She goes on to demonstrate how, in biology, investigating the units and levels of evolving entities lends insight into the hierarchical nature of life, and with her methodology, she points out how evolutionary linguists too need to investigate the ontological status of the units and levels that associate with language and communication, by developing hierarchy theories that enable visualizations of causality. Such investigations will make it possible to synthesise existing theories as well as to commence a more systematic search for what is and what is not relevant to language evolution studies.

Language is a cooperative endeavour that enables individuals to freely and trustworthily exchange information with one another. There exists a somewhat consensus view in the literature that the cooperative nature of language potentially enables the emergence of free-riders, who could manipulatively exploit the system with false messages. Multiple hypotheses have been introduced that explain how such freeriding can become constrained over the course of language evolution in order for the system not to collapse. In "The role of the lie in the evolution of human language", Daniel Dor (2017, this issue) presents an alternative view and investigates how deception and lying might have actually contributed to the evolution of both human cognition and language. Building on his 2015 work, The Instruction of Imagination: Language as a Social Communication Technology (Dor, 2015), Dor understands language as a "social communication technology, collectively designed for the instruction of imagination", that co-evolved with the human capacity to lie. On an emotional and cognitive level, lying enables our capacity to imagine alternative scenarios, and on a social level, lying brings forth new communicative relationships (e.g. lie detection and moral enforcements) that bring forth new means to establish social cohesion. Lying does more for the evolution of language than honest communication, because lying disconnects personal sense-based experiences from messages conveyed, and facilitates imagination, persuasion, and social bonding. Dor concludes that lying must have evolved after honest, experientialmimetic based communication emerged and that lying provided variation in existing communicative strategies. This in turn boosted community formation where language as the instruction of imagination emerged in a co-evolutionary way.

Antonio Benítez-Burraco's contribution "Grammaticalization and language evolution: going another round" (2017, this issue) presents a critical evaluation of the applicability of grammaticalization theory to language origins research. The stakes are high, as grammaticalization theory, by extrapolating the patterns observed in language change on a smaller timescale - is taken to afford insight into language much beyond the temporal scope of traditional historical reconstructions. This, however, depends on the uniformitarian assumption that the processes of language change operating in deep prehistory were not substantially different from historical change observable from the actual records available to linguists. Benítez-Burraco argues that this is far from certain, given the (inferred) differences in language-related cognitive capacities between ancient and modern human populations, and most importantly the identified genetic differences that have been linked to language. Apart from the genetic argument, the author also appeals to the self-domestication hypothesis, which could have led to the changes in social cognition impacting the abilities involved in grammaticalization.

Michael Pleyer (2017, this issue) argues for an interactionist perspective on language evolution. In doing so, he appeals to a vast literature on meaning construal, perspective-taking and the development of shared meaning in interaction. A strong emphasis is put on the emergence of linguistic structures through cultural evolution, which is not limited to mechanisms of cultural-historical change but is emphatically shown to embrace micro-processes operating on a turn-to-turn basis in conversational exchanges. Pleyer summons compelling evidence that these micro-evolutionary processes result in ad-hoc constructions, which are later stabilised and entrenched in the linguistic practices of interactional communities. This leads Pleyer to the argument that the cognitive and social prerequisites facilitating these micro-processes - behavioural resonance, conceptual pacts, intersubjective alignment or local schematisation - are in fact the prerequisites for, first, protolanguage and, 
then, fully fledged language. After reviewing the developmental and primatological literatures on the subject, the author lays out his view on the protolinguistic beginnings of communication and its later development.

In "An evolutionary approach to low-level conversational cooperation," Slawomir Wacewicz, Przemyslaw Zywiczynski and Alessandra Chiera (2017, this issue) explore the roots of cooperation, and specifically, the compatibility of conversation understood as a cooperative activity with the logic of evolutionary game-theory. They distinguish between two layers of conversation: they suggest that the relatively higher level of transmitting content (verbal, propositional messages) rests on, and grows from, the relatively lower level of basic mechanics and structuring. The processes of achieving lower-level coordination between the speakers are nonverbal, unintentional, and not directly related to propositional or even semantic content, but nevertheless appear necessary for maintaining smooth and focused interaction. Wacewicz and colleagues review the relevant literature guided by a simple classificatory principle, i.e. the distinction into mimicry, which is coordination in the form of behaviours (e.g. postural mirroring or the matching of mannerisms), and synchrony, which is coordination in their timing (e.g. turn-taking). The key point of the paper is the role that these two types of low-level phenomena play in forming a socio-emotive scaffolding on which cooperation can progressively develop. Existing evidence for low-level coordination generally helping cooperativeness prompts Wacewicz et al. to speculate how such coordinative processes may also be primary in an evolutionary sense: a possible evolutionary precursor for the increasingly advanced forms of cooperation, including the cooperative information sharing unique to human language.

In "Mental Time Travel and Language Evolution: A Narrative Account of the Origins of Human Communication", Francesco Ferretti, Ines Adornetti, Alessandra Chiera, Serena Nicchiarelli, Rita Magni, Giovanni Valeri, and Andrea Marini (2017, this issue) advocate the view that the origin of language should be traced back to narrativity. Appealing to both theoretical arguments and empirical evidence, the authors propose that it is narrativity that separates linguistic communication from various communication types found in non-human animals. The cognitive infrastructure underlying narrativity is tightly linked to the development of the social brain and mind reading skills, required for understanding communicative intentions. Yet, the authors argue that the social brain hypothesis fails to account for global coherence unique to linguistic communication, whereby language processing crucially depends on the comprehension of pragmatic-discourse organization. Following Corballis (2014), they identify Mental Time Travel (MTT) as the cognitive mechanism indispensable to global coherence, and hence language. At the same time, the two constituents of MTT - Episodic Memory and Episodic Future Memory - are the necessary conditions for narratives, by enabling communicators to relive past experiences and simulate future scenarios (expressed at the level of narrative, respectively, as flashbacks and flash-forwards). Ferretti et al. muster evidence from studies on non-human primates as well as clinical populations, including their own research on autistic patients, to show that MTT is a language-independent skill, which was within the reach of the human-chimpanzee Last Common Ancestors and which could have bootstrapped the emerging faculty of language. Ferretti and colleagues take pantomime as the early, protolinguistic mode of communication they argue that pantomime, on the one hand, relies on non-verbal and non-conventional means of expression that non-human primates are capable of; on the other hand, its capacity to represent past and future events makes it qualitatively different from the communication systems found in non-human apes.

In "Language evolution: how language was built and made to evolve", Bernard Bichakjian (2017, this issue) - a pioneer in the study of the evolution of languages and one of the founding members of the Language Origins Society - takes issue with two lines of thinking defended by biolinguists: a saltationist scenario of language emergence and reduction of language to syntax. Instead of these unrealistic and constraining assumptions, he argues, on the grounds of evolutionary logic and evidence from historical linguistics, that language emerged and evolved gradually through a cross-fertilization process whereby the evolution of linguistic features cross-fertilised the evolution of the biological substratum while the evolution of the biological correlates, especially the central ones, cross-fertilised the evolution of linguistic features. Historical changes are understood as adaptive and cumulative, and phenomena such as the development of grammatical markers, the morphing of aspect-based verbal systems into tense-based alternatives, or the grammaticalisation of sensory roles into syntactic functions are considered to push linguistic systems toward forms that can optimally be processed by the left-hemisphere. As a demonstration of these processes in historical language change, the author looks at a line of evidence related to the evolution of writing from ideographic to alphabetical systems. Bichakjian explains how respective brain processes involved in scanning ideographic and alphabetical systems can be called to account for the Greek reversal of writing, i.e. writing from left to right, rather than from right to left, which is common in ideographic scripts.

\section{Acknowledgements}

Most of the papers in this volume grew from a careful selection of presentations given at Protolang 4 conference that was $^{4}$ held in Rome from September 24th to 26th, 2015, and chaired by Francesco Ferretti. The authors are grateful to Sune Vork Steffensen for providing an excellent venue for this special issue; to the authors for contributing; and to the referees, who must remain anonymous, for providing all of us with valuable comments. Zywiczynski and Wacewicz furthermore acknowledge the research fund of the Faculty of Languages (303/16) at Nicolaus Copernicus University; and Gontier thanks

\footnotetext{
4 The Protolang conference series creates an interdisciplinary platform for scholarly discussion on the origins of symbolic communication distinctive of human beings. The thematic focus of Protolang is on delineating the genetic, anatomical, neuro-cognitive, socio-cultural, semiotic, symbolic and ecological requirements for evolving (proto)language. For more details, see the description at www.protolang.org.
} 
the Portuguese Foundation for Science and Technology (Fundação para a Ciência e a Tecnologia, grant ID SFRH/BPD/89195/ 2012 and project number UID/FIL/00678/2013) for its support.

\section{References}

Akach, P., Demey, E., Matabane, E., Van Herreweghe, M., Vermeerbergen, M., 2009. What is South African sign language? What is the South African Deaf community? In: Brock-Utne, B., Skattum, I. (Eds.), Languages and Education in Africa: A Comparative and Transdisciplinary Analysis. Symposium books, Oxford, pp. 333-347.

Arbib, M., 2012. How the Brain Got Language. Oxford University Press, Oxford.

Armstrong, D.F., Wilcox, S.E., 2007. The Gestural Origin of Language. Oxford University Press, Oxford.

Baldwin, J., 1896. A new factor in evolution. Am. Nat. 30 (354), 441-451.

Bechtel, W., 2011. Mechanism and biological explanation. Philosophy Sci. 78, 533-577.

Beckner, C., Pierrehumbert, J.B., Hay, J., 2017. The emergence of linguistic structure in an online iterated learning task. J. Lang. Evol. http://dx.doi.org/10.1093/ jole/lzx001.

Benítez-Burraco, A., 2017. Grammaticalization and language evolution: focusing the debate. Lang. Sci. http://dx.doi.org/10.1016/j.langsci.2017.03.003.

Berwick, R.C., Chomsky, N., 2016. Why Only Us. The MIT Press, Cambridge, Mass.

Bichakjian, B., 2017. Language evolution: how language was built and made to evolve. Lang. Sci. http://dx.doi.org/10.1016/j.langsci.2017.03.004.

Bickerton, D., 1990. Language and Species. Univ of Chicago Press, Chicago.

Bickerton, D., 2016. Roots of Language. Language Science Press, Berlin.

Botha, R., 2007. On homesign systems as a potential window on language evolution. Lang. Commun. 27 (1), 41-53.

Boyd, R., Richerson, P., 1985. Culture and the Evolutionary Process. Chicago Univ Press, Chicago.

Boysen, S.T., Berntson, G.G., Hannan, M.B., Cacioppo, J.T., 1996. Quantity-based interference and symbolic representations in chimpanzees (Pan troglodytes). J. Exp. Psychol. Anim. Behav. Process. 22, 76-86.

Brandon, R.N., 1982. The levels of selection. In: Brandon, R.N., Burian, R.M. (Eds.), Genes, Organisms, Populations. The MIT Press, Cambridge, Mass, pp. 133-139.

Brown, S., 2001. The "Musilanguage" model of music evolution. In: Wallin, N.L., Merker, B., Brown, S. (Eds.), The Origins of Music. The MIT Press Cambridge, Mass, pp. 271-301.

Burling, R., 2005. The talking ape: how language evolved. Oxford University Press, Oxford.

Campbell, D.T., 1974. Downward causation' in hierarchically organized biological systems. In: Ayala, F.J., Dobzhansky, T. (Eds.), Studies in the Philosophy of Biology. University of California Press, Oakland, Cal, pp. 179-186.

Cheney, D.L., Seyfarth, R.M., 1988. Assessment of meaning and the detection of unreliable signals by vervet monkeys. Anim. Behav. 36 (2), 477-486.

Chomsky, N., 1965. Aspects of the Theory of Syntax. The MIT Press, Cambridge, Mass.

Chomsky, N., 1999. Derivation by Phase. The MIT Press, Cambridge, Mass.

Chomsky, N., 2011. Language and other cognitive systems. What is special about language? Lang. Learn. Dev. 7 (4), $263-278$.

Christiansen, M.H., 1994. Infinite Languages, Finite Minds: Connectionism, Learning and Linguistic Structure. University of Edinburgh, Edinburgh.

de Condillac, É.B., 1756 [1746]. An Essay on the Origin of Human Knowledge [Essai sur l'origine des connaissances humaines] (T. Nugent, Trans.). J. Nourse, London.

Corballis, M.C., 2002. From Hand to Mouth. Princeton Univ Press, Princeton.

Corballis, M.C., 2003. From mouth to hand: gesture, speech, and the evolution of right-handedness. Behav. Brain Sci. 26 (2), $199-208$.

Corballis, M.C., 2014. The gradual evolution of language. Humana Mente Orig. Evol. Lang. 39.

Croft, W., 2000. Explaining Language Change. Pearson, Essex.

Danchin, E., Charmantier, A., Champagne, F., Mesoudi, A., Pujol, B., Blanchet, S., 2011. Beyond DNA: integrating inclusive inheritance into an extended theory of evolution. Nat. Rev. Genet. 12, 475-486.

Darwin, C., 1859. The Origin of Species by Means of Natural Election, Or the Preservation of Favored Races in the Struggle for Life. John Murray, London.

Dawkins, R., 1982. Replicators and vehicles. In: Brandon, N.R., Burian, R.M. (Eds.), Genes, Organisms, Populations. The MIT Press, Cambridge, Mass, pp. $161-179$.

Deacon, T., 1992. The neural circuitry underlying primate calls and human language. In: Wind, J., Chiarelli, B., Bichakjian, B., Nocentini, Jonker, A. (Eds.), Language Origins: A Multidisciplinary Approach. Kluwer, Dordrecht, pp. 121-162.

Deacon, T., 1997. The Symbolic Species. WW Norton, New York.

Deacon, T., 2012. The symbol concept. In: Gibson, K.R., Tallerman, M. (Eds.), The Oxford Handbook of Language Evolution. Oxford University Press, Oxford, pp. 393-405.

Dediu, D., de Boer, B., 2016. Language evolution needs its own journal. J. Lang. Evol. 1, 1-6. http://dx.doi.org/10.1093/jole/lzv001.

Dediu, D., Janssen, R., Moisik, S., 2017. Language is not isolated from its wider environment: vocal tract influences on the evolution of speech and language. Lang. Commun. 54, 9-20. http://dx.doi.org/10.1016/j.langcom.2016.10.002.

Dennett, D., 1995. Darwin's Dangerous Idea: Evolution and the Meanings of Life. Simon \& Schuster, New York.

Donald, M., 1991. Origins of the Modern Mind: Three Stages in the Evolution of Culture and Cognition. Harvard University Press, Cambridge, Mass.

Dor, D., Knight, C., Lewis, J., 2014. Introduction: a social perspective on how language began. In: Dor, D., Knight, C., Lewis, J. (Eds.), The Social Origins of Language. Oxford University Press, Oxford, pp. 1-14.

Dor, D., 2015. The Instruction of Imagination. Oxford Univ Press, Oxford.

Dor, D., 2017. The role of the lie in the evolution of human language. Lang. Sci. http://dx.doi.org/10.1016/j.langsci.2017.01.001.

Dryer, M., Haspelmath, M. (Eds.), 2011. The World Atlas of Language Structures (WALS) Online. Max Planck Digital Library, Munich.

Dunbar, R., 1996. Grooming, Gossip and the Evolution of Language. Faber \& Faber, London.

Dunbar, R., 1998. The social brain hypothesis. Evol. Anthr. 6 (5), 178-190.

Dunbar, R., 2007. The social brain hypothesis and its relevance to social psychology. In: Forgas, J.P., Haselton, M.G., von Hippel, W. (Eds.), Evolution and the Social Mind: Evolutionary Psychology and Social Cognition. Psychology Press, London, pp. 21-31.

Fay, N., Arbib, M., Garrod, S., 2013. How to bootstrap a human communication system. Cogn. Sci. 37 (7), 1356-1367.

Ferretti, F., Adornetti, I., Chiera, A., Nicchiarelli, S., Magni, R., Valeri, G., Marini, A., 2017. Mental time travel and language evolution: a narrative account of the origins of human communication. Lang. Sci. http://dx.doi.org/10.1016/j.langsci.2017.01.002.

Fitch, T., 2000. The evolution of speech: a comparative approach. Trends Cogn. Sci. 4 (7), 258-267.

Fitch, T., 2010. The Evolution of Language. Cambridge University Press, Cambridge.

Fitch, W., 2017. Empirical approaches to the study of language evolution. Psychon. Bull. Rev. 24 (1), 3-33.

Galantucci, B., Garrod, S., 2011. Experimental semiotics: a review. Front. Hum. Neurosci. 5 (11).

Goldin-Meadow, S., 2016. What the hands can tell us about language emergence. Psychon. Bull. Rev., 1-6.

Goldin-Meadow, S., So, W.C., Özyürek, A., Mylander, C., 2008. The natural order of events: how speakers of different languages represent events nonverbally. Proc. Natl. Acad. Sci. 105 (27), 9163-9168.

Gontier, N., 2017. What are the levels and mechanisms/processes of language evolution? Lang. Sci. (in press).

Gould, S.J., Vrba, E.S., 1998. Exaptation: a missing term in the science of form. In: Hull, D., Ruse, M. (Eds.), The Philosophy of Biology. Oxford Univ Press, New York, pp. 52-71.

Griesemer, J., 2000. Development, culture and the units of inheritance. Philos. Sci. 67, S348-S368.

Hauser, M.D., Chomsky, N., Fitch, T., 2002. The faculty of language: what is it, who has it, and how did it evolve? Science 298, 1569-1580. 
Hewes, G.W., 1973. Primate communication and the gestural origin of language. Curr. Anthropol. 14 (1/2), 5-24.

Hewes, G.W., 1977. A model for language evolution. Sign Lang. Stud. 15, 97-168.

Hewes, G.W., 1996. A history of the study of language origins and the gestural primacy hypothesis. In: Lock, A., Peters, C.R. (Eds.), Handbook of Human Symbolic Evolution. Oxford University Press, Oxford, pp. 263-269.

Hrdy, S.B., 2009. Mothers and Others: The Evolutionary Origins of Mutual Understanding. Belknap Press of Harvard, Cambridge, Mass.

Hull, D.L., 1980. Individuality and selection. Annu. Rev. Ecol. Syst. 11, 311-332.

Hurford, J., 2007. The Origins of Meaning. Language in the Light of Evolution. Oxford University Press, Oxford.

Hurford, J., 2012. The origins of meaning. In: Gibson, K.R., Tallerman, M. (Eds.), The Oxford Handbook of Language Evolution. Oxford University Press, Oxford, pp. 370-381.

Huxley, L., 1900. Life and Letters of Thomas Henry Huxley, vol. 2. D. Appleton \& Company, New York.

Jablonka, E., Lamb, M.J., 1999. Epigenetic Inheritance and Evolution: The Lamarckian Dimension. Oxford University Press, Oxford.

Jackendoff, R., 2002. Foundations of Language. Brain, Meaning, Grammar, Evolution. Oxford University Press, New York.

Jespersen, O., 1922. Language: Its Nature, Development and Origin. Allen \& Unwin, London.

Johansson, S., 2005. Origins of Language: Constraints on Hypotheses. John Benjamins, Amsterdam.

Johansson, S., 2008. Seeking compositionality in holistic proto-language without substructure - do counterexamples overwhelm the fractionation process? In: Smith, A., Smith, K., Ferrer-i-Cancho, R. (Eds.), Proceedings of the 7th International Conference on the Evolution of Language. World Scientific, Singapore, pp. 171-178.

Kendon, A., 2008. Signs for language origins? Public J. Semiotics 2, 2-29.

Kendon, A., 2011. Some modern considerations for thinking about language evolution: a discussion of the evolution of language by Tecumseh Fitch. Public J. Semiotics 3 (1), 79-108.

Kendon, A., 2014. The "poly-modalic" nature of utterances and its relevance for inquiring into language origins. In: Dor, D., Knight, C., Lewis, J. (Eds.), The Social Origins of Language. Oxford University Press, Oxford, pp. 67-76.

Kirby, S., Cornish, H., Smith, K., 2008. Cumulative cultural evolution in the laboratory: an experimental approach to the origins of structure in human language. PNAS 105 (31), 10681-10686.

Kirchner, F., 1890. Natura non facit saltus. In: Kirchner, F. (Ed.), Wörterbuch der philosophischen Grundbegriffe. Weis. http://www.textlog.de/1850.html.

Laubichler, M.D., Renn, J., 2015. Extended evolution: a conceptual framework for integrating regulatory networks and niche construction. J. Exp. Zool. B 324, $565-577$.

Leibniz, G., 1996 [1765]. New essays on human understanding. In: Translated and Edited by Peter Remnant and Jonathan Bennett, second ed. Cambridge University Press, New York.

Levinson, S.J., Holler, J., 2014. The origin of human multi-modal communication. Philos. Trans. R. Soc. B Ser., 369. http://dx.doi.org/10.1098/rstb.2013.0302. Levinson, S., 2006. On the human interactional engine. In: Enfield, N.J., Levinson, S. (Eds.), Roots of Human Sociality. Culture, Cognition and Human Interaction. Berg, New York, pp. 39-69.

Lewontin, R., 1970. The levels of selection. Annu. Rev. Ecol. Syst., 1-18.

Liebal, K., Waller, B.M., Slocombe, K.E., Burrows, A.M., 2013. Primate Communication: A Multimodal Approach. Cambridge University Press, Cambridge. Lieberman, P., 2001. Human Language and Our Reptilian Brain. Harvard University Press, Cambridge, Mass.

Lieberman, P., 2007. The evolution of human speech: its anatomical and neural bases. Curr. Anthropol. 48 (1), 39-66.

Lupyan, G., Dale, R., 2010. Language structure is partly determined by social structure. PloS One 5 (1), e8559.

Machamer, P., Darden, L., Carver, C.F., 2000. Thinking about mechanisms. Philosophy Sci. 67 (1), 1-25.

MacLarnon, A.M., Hewitt, G.P., 1999. The evolution of human speech: the role of Enhanced Breathing control. Am. J. Phys. Anthropol. 109 (3), $341-363$. MacNeilage, P.F., 2008. The Origin of Speech. Oxford University Press, Oxford.

Masel, J., 2011. Genetic drift. Curr. Biol. 21 (20), R837-R838.

Maynard Smith, J., Szathmáry, E., 1995. The Major Transitions in Evolution. Oxford Univ Press, New York.

Mayr, E., 1961. Cause and effect in biology. Science 134 (3489), 1501-1506.

McNeill, D., 2012. How Language Began: Gesture and Speech in Human Evolution. Cambridge University Press, Cambridge.

Mesoudi, A., 2016. Cultural evolution: integrating psychology, evolution and culture. Curr. Opin. Psychol. 7, 17-22.

Miłkowski, M., 2016. Integrating cognitive (neuro)science using mechanisms. Avant 7 (2), 45-67.

Mithen, S., 2005. The Singing Neanderthals: The Origins of Music, Language, Mind and Body. Weidenfeld and Nicholson, London.

Nishimura, T., Mikami, A., Suzuki, J., Matsuzawa, T., 2003. Descent of the larynx in chimpanzee infants. Proc. Natl. Acad. Sci. 100 (12), $6930-6933$.

Okasha, S., 2006. Evolution and the Levels of Selection. Oxford University Press, Oxford.

Okasha, S., 2005. Multilevel selection and the major transitions in evolution. Biol. Philos. 72, 1013-1025.

Oyama, S., Griffiths, P.E., Gray, R.D., 2001. Cycles of Contingency. The MIT Press, Cambridge, Mass.

Perlman, M., Dale, R., Lupyan, G., 2015. Iconicity can ground the creation of vocal symbols. R. Soc. Open Sci. 2 (8), 150-152.

Pigliucci, M., Finkelman, L., 2014. The extended (evolutionary) synthesis debate: where science meets philosophy. BioScience 64, 511-516.

Pinker, S., 2003. Language as an adaptation to the cognitive niche. In: Christiansen, M., Kirby, S. (Eds.), Language Evolution. Oxford University Press, Oxford, pp. $16-37$.

Pinker, S., Bloom, P., 1990. Natural language and natural selection. Behav. Brain Sci. 13 (4), 707-784.

Pleyer, M., 2017. Protolanguage and mechanisms of meaning construal in interaction. Lang. Sci. http://dx.doi.org/10.1016/j.langsci.2017.01.003.

Premack, D., Woodruff, G., 1978. Does the chimpanzee have a theory of mind? Behav. Brain Sci. 1 (4), 515-526.

Sandler, W., 2013. Vive la différence: sign language and spoken language in language evolution. Lang. Cogn. 5 (2-3), 189-203.

Senghas, R.J., Senghas, A., Pyers, J.E., 2005. The emergence of Nicaraguan sign language: questions of development, acquisition, and evolution. In:

Senghas, R.J., Senghas, A., Pyers, J.E., Langer, J., Parker, S.T., Milbrath, C. (Eds.), Biology and Knowledge Revisited: From Neurogenesis to Psychogenesis. Psychology Press, London, pp. 287-306.

Smith, A., 2008. Protolanguage reconstructed. Interact. Stud. 9 (1), 100-116.

Steels, L., Szathmáry, E., 2008. Replicator dynamics and language processing. In: Smith, A.D.M., Smith, K., Ferrer i Cancho, R. (Eds.), The Evolution of Language: Proceedings of the 7th International Conference. World Scientific, Signapore.

Stokoe, W.C., 2001. Language in Hand: Why Sign Came Before Speech. Gallaudet University Press, Washington, DC.

Szathmáry, E., 2006. The origins of replicators and reproducers. Philos. Trans. R. Soc. B Biol. Sci. 361, 1761-1776.

Tallerman, M., 2008. Holophrastic protolanguage: Planning, processing, storage, and retrieval. Interact. Stud. 9 (1), 84-99.

Tallerman, M., 2011. Protolanguage. In: Gibson, K., Tallerman, M. (Eds.), The Oxford Handbook of Language Evolution. Oxford University Press, Oxford, pp. 479-491.

Tamariz, M., Kirby, S., 2016. The cultural evolution of language. Curr. Opin. Psychol. 8, 37-43.

Tattersall, I., 2010. Human evolution and cognition. Theor. Biosci. 129 (2-3), 193-210.

Tinbergen, N., 1963. On aims and methods of ethology. Zeitschrift für Tierpsychologie 20, 410-433.

Tomasello, M., 1999. The Cultural Origins of Human Cognition. Harvard University Press, Cambridge, Mass.

Tomasello, M., 2008. Origins of Human Communication. The MIT Press, Cambridge, Mass.

Tomasello, M., Call, J., 1997. Primate Cognition. Oxford University Press, New York.

Vico, G., 1948 [1725]. [Scienza Nuova di Giambattista Vico] The New Science of Giambattista Vico (T.G. Bergin, Trans.). Cornell University Press, Ithaca.

Wacewicz, S., Zywiczynski, P., 2012. Beyond protolanguage. Contemporary problems in the evolution of language. Theor. Hist. Sci. 9, 5-11. 
Wacewicz, S., Żywiczyński, P., Chiera, A., 2017. An evolutionary approach to low-level conversational cooperation. Lang. Sci. http://dx.doi.org/10.1016/j. langsci.2017.01.005.

Wacewicz, S., Zywiczynski, P., Orzechowski, S., 2016. Visible movements of the orofacial area. Evidence for gestural or multimodal theories of language evolution? Gesture 15 (2), 250-282 http://dx.doi.org/10.1075/gest.15.2.05wac.

West-Eberhard, M.J., 2005. Phenotypic accommodation: adaptive innovation due to developmental plasticity. J. Exp. Zool. (Mol. Dev. Evol.) 304B, 610-618.

Wray, A., 1998. Protolanguage as a holistic system for social interaction. Lang. Commun. 18, 47-67.

Wray, A., Grace, G.W., 2007. The consequences of talking to strangers: evolutionary corollaries of socio-cultural influences on linguistic form. Lingua 117 (3), $543-578$.

Zlatev, J., 2008. The co-evolution of intersubjectivity and bodily mimesis. In: Zlatev, J., Racine, T., Sinha, C., Itkonen, E. (Eds.), The Shared Mind: Perspectives on Intersubjectivity. John Benjamins, Amsterdam, pp. 215-244.

Zlatev, J., Wacewicz, S., Zywiczynski, P., van de Weijer, J., 2017. Multimodal-first or pantomime-first? Communicating events through pantomime with and without vocalization. Interact. Stud. (3).

Zywiczynski, P., Wacewicz, S., Sibierska, M., 2016. Defining pantomime for language evolution research. Topoi. http://dx.doi.org/10.1007/s11245-0169425-9.

Zywiczynski, P., Wacewicz, S., 2015. Ewolucja języka. W stronę hipotez gesturalnych. Wydawnictwo Uniwersytetu Mikołaja Kopernika, Toruń.

Przemyslaw Zywiczynski* CLES - Center for Language Evolution Studies, Nicolaus Copernicus University, Poland

Nathalie Gontier AppEEL - Applied Evolutionary Epistemology Lab, Centre for Philosophy of Science, University of Lisbon, Portugal

Slawomir Wacewicz CLES - Center for Language Evolution Studies, Nicolaus Copernicus University, Poland

* Corresponding author. E-mail address: przemek@umk.pl 